\title{
Cerebrospinal fluid ascites: a complication of a ventriculoperitoneal shunt
}

\author{
DAVID F. DEAN ${ }^{1}$ AND IRVIN B. KELLER \\ From the Wilford Hall USAF Medical Center, Lackland Air Force Base, Texas, U.S.A.
}

SUMMARY A 1 year old Caucasian male born with an omphalocoele, malrotation of the large bowel, and Ladd's bands developed an $E$. coli wound infection and subsequent meningitis-ventriculitis which responded to antibiotic therapy. Aqueductal stenosis and obstructive hydrocephalus initially was treated with a ventriculoperitoneal shunt. After a routine diphtheria-pertussis-tetanus immunization, the child developed a CSF ascites which resolved following a ventriculoatrial shunt.

Large abdominal cysts have been reported as a complication of ventriculoperitoneal shunts (Harsh, 1954; Jackson and Snodgrass, 1955; Scott, Wycis, Murtagh, and Reyes, 1955; Ames, 1967; Murtagh and Lehman, 1967; Fischer and Shillito, 1969). The seven reported to date were primarily thought to have developed as a result of prior inflammatory phenomena related to other abdominal procedures or infection (Ames, 1967; Fischer and Shillito, 1969). We believe that response to a routine immunization led to the development of a malabsorption of cerebrospinal fluid (CSF) from the peritoneal cavity in a patient who had already been compromised by prior abdominal surgery. In this institution, the ventriculoperitoneal shunt has often been a first choice procedure in the management of a hydrocephalic child or in one who had infected his first ventriculoatrial (VA) shunt, or in the premature neonate hydrocephalic whose veins are small. By avoiding an early VA shunt, we hope to decrease multiple shunt procedures in the first year of life. The following case is reported because of a CSF malabsorption without discernible cyst formation.

\section{CASE REPORT}

This 9 month old Caucasian male was noted at birth to have an omphalocoele which was repaired

1 Present address: Neurosurgery Service, USAF Medical Centre, Keesler AFB, Mississippi, 39534, U.S.A. primarily at 12 hours of age. His weight was $2.8 \mathrm{~kg}$ (6 lb. $1 \mathrm{oz}$ ), Apgar score 8/9. For two days he did not feed well, then developed some abdominal distension and vomiting. At 3 days of age an exploratory $\omega_{w}$ laparotomy disclosed partial malrotation of the $A$ large bowel and Ladd's bands. These were lysed an $\Phi$ the rotation corrected.

Subsequently the child developed an $E$. coळ 음 wound infection, as well as a meningitis and ven triculitis. The infection responded to a combination of methicillin, kanamycin (Kantrex), intravenous cephalothin (Keflin), polymyxin-B, chlorampheni< $\mathrm{col}$, and intraventricular polymyxin-B. After the $\overrightarrow{0}$ latter the protein in his CSF increased to $3 \mathrm{~g} / 100 \mathrm{mF}$. N and head size increased. At 52 days of age his occipitofrontal circumference was $40.5 \mathrm{~cm}$ and increased at the rate of $0.5 \mathrm{~cm}$ per day. A ventriculogram demonstrated obstruction at the aqueduct. At 55 days of age a ventriculoperitoneal shunt was performed. At that time the child also had a cardiac murmur consistent with either pulmonic stenosis or a ventriculoseptal defect.

The child did well until 6 months of age when he began to vomit, became irritable, and his head began to grow. The distal end of his shunt appeared to be functioning but the proximal end was filled with brain debris. The ventricular end was revised and the child did well until 8 months when he was given a routine diphtheria-pertussis-tetanus (DPT) immunization. That evening the child's temperature rose to $39.4^{\circ} \mathrm{C}\left(103^{\circ} \mathrm{F}\right)$ rectally; he was fretful and anorexic for two days and then his parents noted that the child's abdomen began to increase in girth. Within $\mathbf{1 0}$ days he was readmitted to the hospital because of abdominal distension, vomiting, and respiratory distress (Figure). 
Serum bilirubin and enzymes were normal. His abdomen was tapped as well as his shunt. The ascitic fluid was slightly straw-coloured and contained $900 \mathrm{mg}$ protein, $75 \mathrm{mg}$ glucose per $100 \mathrm{ml}$. and 7 lymphocytes and 2 polymorphonuclear leucocytes per c.mm. Cerebrospinal fluid contained $100 \mathrm{mg}$ protein and $55 \mathrm{mg}$ glucose per $100 \mathrm{ml}$. and 2 lymphocytes per c.mm. Gram stains on both were negative, as were cultures. Abdominal insufflation did not demonstrate any cyst.

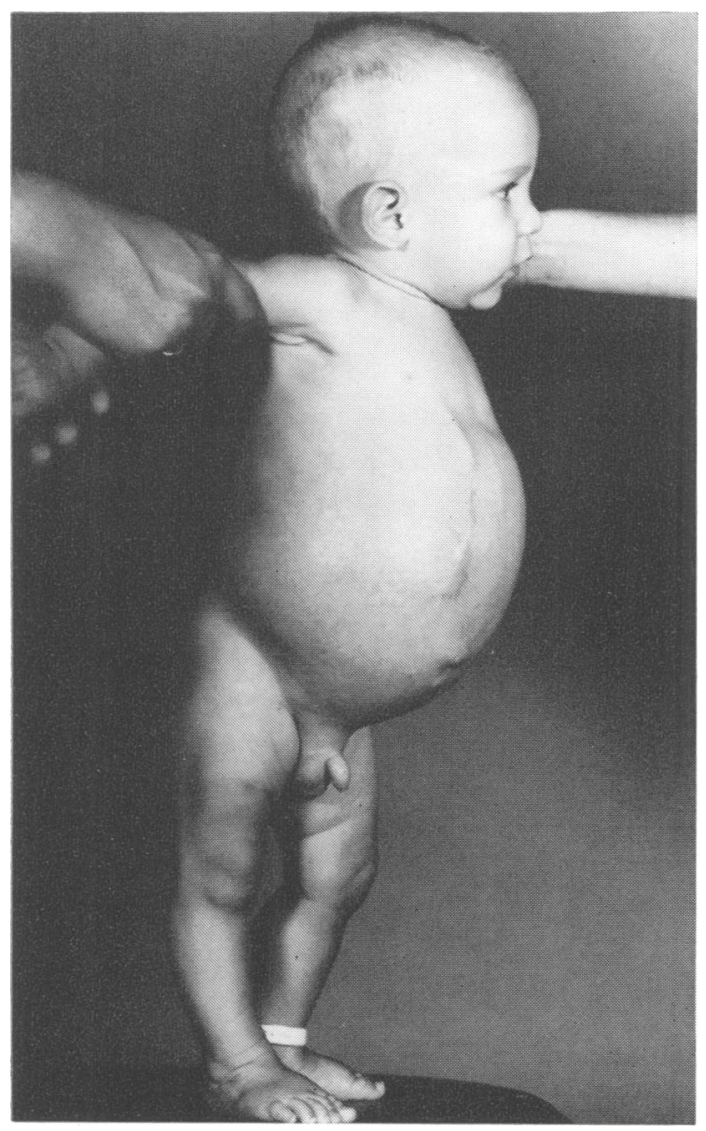

FIGURE Nine month old patient with massive CSF ascites.

For six weeks he was followed as an outpatient, and required several abdominal paracenteses because of respiratory distress as his abdominal girth began to exceed $68 \mathrm{~cm}$. At age 9 months his heart murmur disappeared and the child was admitted for elective ventriculoatrial shunt. His postoperative course was benign. His ascites cleared and at three month follow-up the child has done well and has met milestones normal for age.

\section{DISCUSSION}

In the cases described by Harsh (1955), and Fischer and Shillito (1969) all four had abdominal surgery. Ames (1967) mentioned one case of a series of approximately 120 ventriculoperitoneal shunts he had performed in which the child had an acute febrile illness which was followed three weeks later by decreased CSF absorption and the child 'rejected' his shunt. It may be that the child developed mesenteric adenitis or an omental or peritoneal inflammation that reversed its absorptive capacity. Similarly the reasons for the shunt 'rejection' in our case remain speculative. It is interesting to note that the patient's shunt continued to function sufficiently well so that his intracranial pressure did not rise, nor his head circumference increase.

We cannot help but speculate that the antigenantibody response to a routine DPT immunization in our patient began the process that led to the malabsorption in the patient's peritoneal cavity which had been previously compromised by infection and surgery. Ordinarily we would not have chosen to have performed a ventriculoperitoneal shunt in this child because of the previous history of surgery and infection. However, because of the cardiac murmur and the chances of septicaemia and further cardiopulmonary complications, the peritoneum seemed to be the lesser of two evils. The initial function of the shunt demonstrated that surgery and infection had not sufficiently damaged the absorptive capabilities of the cavity to preclude its safe use. We must conclude that in future cases we will be reluctant to recommend routine immunizations unless omission of this would constitute an evident hazard to the child.

\section{REFERENCES}

Ames, R. H. (1967). Ventriculo-peritoneal shunts in the management of hydrocephalus. Journal of Neurosurgery, 27, 525-529.

Fischer, E. G., and Shillito, J., Jr. (1969). Large abdominal cysts: a complication of peritoneal shunts. Report of three cases. Journal of Neurosurgery, 31, 441-444. 
Harsh, G. R. III (1954). Peritoneal shunt for hydrocephalus utilizing the fimbria of the fallopian tube for entrance to the peritoneal cavity. Journal of Neurosurgery, 11, 284-294.

Jackson, I. J., and Snodgrass, S. R. (1955). Peritoneal shunts in the treatment of hydrocephalus and increased intracranial pressure. A 4-year survey of 62 patients. Journal of Neurosurgery, 12, 216-222.
Murtagh, F., and Lehman, R. (1967). Peritoneal shunts in $\mathrm{O}$ the management of hydrocephalus. Journal of the American Medical Association, 202, 1010-1014.

Scott, M., Wycis, H. T., Murtagh, F., and Reyes, V. (1955). Observations on ventricular and lumbar subarachnoid peritoneal shunts in hydrocephalus in infants. Journal of $\subseteq$ Neurosurgery, 12, 165-175. 